\title{
Seeing in the Dark
}

We also have to work, though, sort of the dark side, if you will. We've got to spend time in the shadows in the intelligence world. . . It is a mean, nasty, dangerous dirty business out there, and we have to operate in that arena.

-DICK CHENEY, MEET THE PRESS, SEPTEMBER 16, 2001

Here in the pre-dawn darkness of Afghanistan, we can see the light of a new day on the horizon. ... [T]hrough dark days we have drawn strength from ... the ideals that have guided our nation and lit the world: a belief that all people are created equal, and deserve the freedom to determine their destiny. That is the light that guides us still.

-BARACK OBAMA, PRESS CONFERENCE, MAY 1, 2012

It's all working out. Just remember, everything that you're seeing, everything that you're reading, it's not what's happening.

-DONALD TRUMP, SPEAKING TO VETERANS, JULY 24, 2018

The statements in this chapter's epigraph punctuate a dramatic period in the history of the United States. In the early days of a postmillennium presidency, just two weeks after the terrorist attacks of September 11, 2001, Vice President Dick Cheney presaged that the country would be forced to "work . . . the dark side" and "spend time in the shadows" to wage a battle for which there would be "no end date." Signaling an end to the (relative) peace and prosperity of the prior decade, this new world was "mean, nasty, dirty dangerous," and survival in this landscape would require "any means at our disposal." Though he was referring to the government's planned approach to dealing with terrorist threats, in hindsight his remarks foretell the long period of deep political turmoil and conflict over events yet to come, events that included revelations of secret prisons, torture, human rights abuses, over a hundred thousand civilian causalities, two wars abroad, and an unprecedented erosion of civil liberties for average citizens at 
home. In the midst of this political conflict, the country was further shaken by the worst economic crisis since the Great Depression.

Just over a decade later, on the anniversary of the death of Osama bin Laden, however, President Barack Obama reassured the public that this period of darkness was over. The country had emerged from the "dark cloud of war" and was basking in "the light of a new day." Finally, we could rekindle the ideals that "have guided our nation and lit the world." The optimism of Obama's rhetoric notwithstanding, the end of the war that his comments foreshadowed has yet to arrive. Although it had moved off of the front page with the targeted killing of bin Laden in 2011, Obama maintained a sizable ground force in Afghanistan and dramatically expanded covert drone operations in multiple countries over the course of his two terms in office. Rather than ending, the war had, it appeared to his critics, simply slipped even further into the shadows.

Indeed, Donald Trump's comments at a ceremony honoring military veterans sought to reassure them that the negative war coverage they saw in the news wasn't an accurate reflection of reality, and that "it's all working out." The unpopular war he was referring to, however, wasn't the war on terror that many in his audience had fought in over the prior sixteen years in Iraq and Afghanistan, but rather the trade war that he had launched with China and other countries by introducing tariffs on various imported goods. The other war, the one in Afghanistan (which fifteen thousand US troops were still actively fighting at the time that he spoke), had receded so far from the mainstream conversation that Trump mentioned it only once, almost in passing.

While these remarks reflect widely varying politics and illuminate different points in the ongoing tide of the longest-running war in US history, they all rely on metaphors of vision and light-optics and occlusion-to signify this period of political instability and national uncertainty. The war they implicitly or explicitly reference is the ongoing war in Afghanistan, which began shortly after Cheney's remarks - part of the amorphous and ongoing war on terror. Where Cheney wants to prepare the public for the darkness and secrecy to come and Obama wants to signal a return to transparency and openness, Trump wants to shift public attention elsewhere entirely. All three men evoke images of conflict and darkness, but differ on whether it is beginning, ending, or simply not what it seems. What was this period of darkness?

The question elicits a range of possibilities, from the horrific nature of various historical events, to the disastrous, at times unethical, reactions of the leaders tasked with responding to them, to the acute polarization and political conflict that surrounded them. But it also emerges in part from the struggle to find sufficient images to represent and therefore comprehend historic events that were for many unbelievable. I do not mean that there were no images of these events-quite the opposite. The 9/11 attacks were widely viewed live on television, and the ensuing invasions of Iraq and Afghanistan were extensively covered on television through 
the military's embedded reporting program. Even events and policies hidden from the public and official media channels (the execution of Saddam Hussein, the torture program at Abu Ghraib, the drone program) produced a gusher of "leaked" images to fill the void. Nor am I referring specifically to places like the "Salt Pit" near Bagram Air Base or policies like "extraordinary rendition," which remained largely hidden from public view. ${ }^{1}$

Instead, our lack of sufficient images was a reflection of the political instability that the country faced at the dawn of a new historical period, one whose contours and dynamics were still occluded from view. Just as optical "seeing" often serves as a metaphor for cognitive understanding ("I see what you mean"), representing something in an image implies the ability to encapsulate and convey this understanding to another person. The period of darkness that emerged in the shadow of 9/11 was cast by our inability to understand or respond in a collective way to the events that unfolded as the war on terror began. In literal and metaphorical terms, we were unable to "picture" what was happening, incapable of "visualizing" a proper response. Instead of the "just" image we needed to shed light on our situation, we just had images-to reference Jean-Luc Godard's well-known turn of phrase. ${ }^{2}$

The optics of this dark period were, paradoxically, partially pushed forward into new territory by the same force that had driven their technological development for much of the previous two centuries: warfare. As scholars such as Paul Virilio, Friedrich Kittler, Lisa Parks, and Roger Stahl demonstrate, the connections between warfare and optical technology run deep, extending down into the classified realm of military research-where weapons development spins off into consumer technology and out into the popular culture, where in turn war and entertainment easily pass for one and the same spectacle. ${ }^{3}$ Where the old model of two nationstates squaring off on the battlefield gave way to newer forms of urban guerilla combat and invisible insurgencies, modern military weaponry turned to the use of information and digital technology_cellular and satellite networks - to track and attack a disparate and disconnected enemy on a global battlefield. The complicity between the state, the military, and the entertainment industry that Tim Lenoir and Luke Caldwell powerfully outline demonstrates how all three collude in producing and profiting from the spectacle of war in society. ${ }^{4}$ The blurring of legal and political lines between previously distinct entities and activities-like that between civilians and insurgents, or between military engagement and nation-building-produced a state of generalized confusion. ${ }^{5}$ For Trump and his supporters, even the press and its coverage of these events became an "enemy of the American people". 6 These conflicts contributed to the larger impression that the United States was in the dark about who and where its enemies were-an impression mirrored in the increasingly "optic-less" and invisible form of warfare that the nation was waging.

But even as military strategy and government policy evolved and expanded to face these invisible threats, activists and protest groups took up similar technologies 
to expose and oppose these actions, a resistance that also drove the evolution of new forms of visual representation. ${ }^{7}$ The opposition to these uses outlined above shaped their evolution as well. For as long as there have been optical recording technologies, there have been representations that sought to counter or contest their official, state-sanctioned use. Many of the filmmakers who pioneered these oppositional modes focused on altering the camera technology-effectively, hacking-as a way of altering or hacking the larger political and commercial framework in which it was developed. ${ }^{8}$ This most recent period was no exception. As historical events forced the United States (in Cheney's eyes at least) to take unprecedented steps, these actions provoked reactions on the part of activists, artists, and everyday citizens. Like Cheney, these dissenting voices were forced to "work . . . the dark side," using "any means at our disposal" to articulate and disseminate their opposing viewpoints.

The result was an explosion of experimentation in nonfiction visual representation, one that combined older technologies like photography, film, and video with newer technologies like digital networks, social media, video games, and data visualization. These new, hybridized forms combined documentary aesthetics, political rhetoric, and digital technology. The same political instability that produced the war on terror brought each of the above fields into concert with one anothera development that produced a radical evolution in the technology we use to record and represent the world and ushered in the emergence of a new "worldview." What brought us through the darkness was not a new technology, but rather a new way of seeing the world itself. This new way of seeing wasn't a product solely of the technology, the state, and the commercial institutions that developed it or the individuals who adopted and adapted it, but rather of the political conflicts and commitments that drove all three.

The birth of this new worldview is the focus of the text that follows. This book's title, Where Truth Lies, describes the space of transition from one worldview to another, a space where the disruption of what once seemed solid and trustworthy (or "true") forced the search for a new "truth" to replace what was lost. Rather than an absolute definition of "truth," it explores how the failure of existing representational paradigms to account for and describe a world that had suddenly been plunged into "darkness" compelled the creation of new paradigms on different representational ground. The space of experimentation between destruction and rebuilding-its own "ground zero" of sorts-is the space that this book explores. It emerges in the overlapping border of the three territories described above: politics, aesthetics, and technology. The competing worldviews it outlines are as much products of the dominant geopolitical regime (referred to in various contexts as "neoliberalism," "multinational capitalism," "vectoral capitalism," or "empire") as they are given forms of technological media or the aesthetic representations that they produce..$^{10}$ In this sense, the disruptions that occurred in the last decade 
reshuffled what Jacques Rancière refers to as the "distribution of the sensible." As Rancière puts it, "[T] he distribution of the sensible is the system of self-evident facts of sense perception that simultaneously discloses the existence of something in common and the delimitations that define the respective parts and positions within it." "11 The redefinition of where truth lies can be understood as a reorganizing of the "self-evident facts" and social relations that make up Rancière's distribution of the sensible. It is, in other words, a redistribution of the sensible.

Positioned at the cusp of film and digital media, this redistribution sits between what was clearly the dominant medium of the twentieth century (the moving image) and what is arguably becoming the dominant medium of the twenty-first century (digital technology and the Internet). ${ }^{12}$ But the emergence of any new medium does not dictate the disappearance of its predecessors. Just as film did not eliminate its forerunners (still photography and print) and went on to survive the emergence of broadcast technologies like radio and television, moving images in general will survive and migrate over into new digital formats and distribution technologies. ${ }^{13}$ And yet, this migration will inevitably change the nature of moving images, even as moving images equally impact the nature of these new media. Film, for example, may have survived and influenced the emergence of its movingimage counterpart, television, but it became nonetheless significantly different as a result. Similarly, film, television, and any number of other existing media continue to shape and be shaped by their integration with evolving digital technologies. The broad intersection of moving images and digital media thus represents the major media transition point occurring today. ${ }^{14}$

What follows focuses specifically on the interactions between one particular type of moving image-the political documentary-and the different ways it shapes and is shaped by digital media. Working at a transitional point in an ongoing historical process that is neither uniform nor monolithic, I explore a range of documentary and digital materials that bear the marks of their mutual influences to varying extents. Some of these texts are clearly recognizable as traditional, feature-length documentary films, and yet they nonetheless bear the imprint of digital technology in both form and content. Other works are "born" digital and lack any photographic, cinematic, or indexical trace, and yet they nonetheless fit within a broad documentary framework by virtue of their rhetorical contexts and political agendas. These hybrid media can be explained to a limited extent as either documentaries or new media, but they are best understood as some mixture of both. ${ }^{15}$

Political documentary and its long-standing connections to grassroots activism and independent media provide the ideal context for understanding much of the political activity taking place online and offline throughout this historical period. ${ }^{16}$ At its root, documentary film collects information about the world, organizes this data into a socially meaningful form, and then presents this information to the 
public. In the context of political documentary, where abstract values like "justice" and "freedom" are called upon to address specific historical circumstances or social conditions, these aesthetic practices take on the role of rhetorical strategies intended to inform and persuade the public. ${ }^{17}$ As an aesthetic practice, documentary instantiates or manifests this meaning through a variety of expressive codes, including framing, editing, exposure, sound, and so forth. When social conceptions of truth and meaning change over time, documentary aesthetics shape and are shaped by these wider ideological shifts.

This mode of aesthetic expression-organizing information into a socially meaningful form-also describes a great deal of the activity taking place in online environments. Indeed, a corporation like Google expresses this boldly in its mission statement, which proclaims that it wants to "organize the world's information." Although a digital form like a website or a database is not simply another form of documentary film, the same impulse to inform, educate, and persuade that gave rise to documentary film in previous periods shapes a great deal of the work being done through digital means. Moreover, documentary's long traditions of participant/independent media production, archival exploration, and social discourse/action all find correlates in interactive environments that seek to enable user-generated content, tagging, and social networking. Both expressions draw on the same social and political impulses, seek the same outcomes, and inform one another's execution even as they differ in the forms of meaning-making they undertake.

If part of the ideological disruption and redistribution that I describe lies in the interactions between these two forms of media, the rest of it lies in the specific political climate that emerged during the presidency of George W. Bush. ${ }^{18}$ The extreme controversy generated first by his election in 2000 (the first of many close elections that reminded the electorate that "participation matters") and continuing through his handling of the 9/11 terrorist attacks ignited heated political debates throughout his term in office. These debates increasingly found expression through documentary means in online environments. Moreover, his administration's general antipathy toward the media and any type of transparency regarding its decisions and their consequences unsurprisingly fed a drive toward independent investigation and expression by both ends of the political spectrum. Indeed, Dick Cheney's assertion about the need to "work ... the dark side" and "spend time in the shadows" also inadvertently came to characterize the administration's generally secretive approach. Consequently, the Bush administration became a natural target for a genre like documentary, steeped as it is in the Enlightenment ideal of transparency. This genre itself was in the midst of migrating to an environment that found its own mantra in Stewart Brand's well-known claim that "information wants to be free."

As the discrepancy between Cheney's policy of secrecy and Brand's mantra of transparency indicates, there is a discursive conflict between state politics and 
digital culture in the years after 9/11. These political debates and broader discussions about the Internet find themselves enmeshed in questions of information, democracy, human rights, truth, and the competing interests of the individual and society. From its inception, the war on terror was conceptualized both implicitly and explicitly as a war of information. Intelligence failures like the inability to predict the $9 / 11$ attacks and the mistaken belief in weapons of mass destruction in Iraq were characterized as resulting from either a lack of information or the fabrication of information to lead the country into war. The controversial use of torture, on the other hand, is approached as a punishment of the body to access information in the mind. ${ }^{19}$ Similarly, the spread of the Internet and networked culture are repeatedly evangelized as an information revolution ushering in an era of collective intelligence and universal access to information. As the torture debates were weighing out the relative importance of individual human rights vis-à-vis society's perceived need for safety, Internet communities were embracing Web 2.0 technologies to empower a cacophony of individual voices to be heard even as these individual voices were orchestrated into mass consensus (as a collectively authored site like Wikipedia illustrates). ${ }^{20}$ Edward Snowden's shocking revelations that the US government was effectively spying on its citizens by covertly collecting information about the communications of its citizens sparked intense debate about privacy and state security. ${ }^{21}$ As neocolonial political debates were waged about the need to bring democracy to the Middle East, the Internet was hailed as a democratizing source of information and positioned as the new public sphere that would return the demos to its rightful center at the heart of public life.

The meeting point between these discourses-between secrecy and the free flow of information, between darkness and exposure-is political documentary media. With its long tradition of alternative/activist media, political rhetoric, information dissemination, and collective spectatorship, documentary was ideally positioned to address both the prominent political questions that came to the fore during this period and the competing utopian and dystopian claims about the role of digital media in public life.

\section{THE DIGITAL DOCUMENTARY}

While the connections between each of these three areas of focus represent mature fields of research (film and digital media, documentary film and politics, politics and new media), the specific area this book addresses remains surprisingly underexplored. This is an odd omission for several reasons. First, significant moments in the development of documentary form and subject matter have repeatedly accompanied and coincided with developments in the technology used to produce and distribute these films. Discussions of the Direct Cinema and Cinema Verité movements of the 1960s almost as a rule begin with accounts of the development of production technologies such as improved $16 \mathrm{~mm}$ film stock, 
wireless sync sound, and lighter, more mobile cameras. ${ }^{22}$ And no less important to the Direct Cinema movement early on was the distribution these films received through television networks-another (relatively) new technology at the time. Both developments shaped how the films were made and seen by altering their content, form, and audience. ${ }^{23}$

Given the role technology played in prior moments, the emergence of digital video cameras, nonlinear editing, and streaming video on the Internet would seem to portend another period of rapid evolution. The explosion of streaming platforms such as Netflix and Amazon and the popularity and prominence of documentary content within these platforms partially demonstrate this. ${ }^{24}$ But we should be wary of concluding that digital technology has simply ushered in a utopian better/faster/cheaper era for documentary film. Indeed, the move from the big screen of the theater at film festivals and organizational meetings to the small screen of the computer, smartphone, or flat-panel display in the home clearly involves a number of trade-offs for filmmakers, particularly in a genre where collective viewing is often fantasized as a form of collective action. Furthermore, a simple increase in image quality through camera technology, for example, has little effect on the quality of the final film as a film. Quoting Godard again, "There's no point in having sharp images when you have fuzzy ideas." ${ }^{25}$ Nonetheless, these technological shifts did provide a number of benefits for documentary filmmakers, including expanded access to less expensive, higher-quality production equipment and a greater diversity of distribution options. ${ }^{26}$

Beyond improvements to image quality and distribution channels, the synthesis of digital technology and documentary film also produced more formally radical experimentation. This book will follow some of these experiments, seeking to locate them within the liminal space between the longer documentary tradition and the burgeoning applications of digital media. Doing so establishes the underexplored influence that documentary (its practices, ethics, and practitioners) had on digital media during a period when digital media was itself rapidly evolving and establishing a dominant presence in everyday life.

\section{THE POLITICAL DOCUMENTARY}

Exploring the impact of film and digital technology on documentary aesthetics implies a determinist connection between the two-a specter that haunts any study of the emergence of a new technology. ${ }^{27}$ The influence of technology undoubtedly forms a key component of this evolution, but it is only one part of the equation. The radical formal innovation that this book connects with technology has also occurred during other historical moments. Documentary as the branch of filmmaking focused on the historical world has always been influenced by shifts in the society that it seeks to reflect and influence. Rather than a smooth development 
between history, aesthetics, and technology, documentary evolves at moments of historical rupture and social crisis: wars, economic depressions, and cultural revolutions. These underlying events and the political conflicts they expose are what drive the changes that I describe here. As historical events create specific challenges for society, filmmakers respond to these challenges by utilizing new and existing technologies to forge new rhetorical, formal, and aesthetic gestures.

Documentary as a genre is a notoriously capacious concept that covers a heterogeneous variety of rhetorical modes and poetic registers, from state propaganda to cultural ethnography to autobiographical expression. However, certain historical periods appear to have pushed the integration of new technology into the wider documentary lexicon. In particular, three prior historical moments reveal an evolution similar to the digital evolution I am addressing: (1) the 1930s and 1940s; (2) the late 1960s and early 1970s; and (3) the late 1980s and early 1990 s. At each of these points, documentary filmmakers utilized new forms of technology to respond to specific social and political crises. In the 1930 and 1940s, filmmakers such as John Grierson, Pare Lorentz, Frank Capra, and Leni Riefenstahl utilized new sound technologies to create state-sponsored films that addressed social issues related to the Great Depression and World War II. Their films utilized what would eventually be termed "voice of God" narration to articulate the aims and nationalist endeavors of the state. As previously mentioned, in the 1960 s and 1970s, American Direct Cinema filmmakers and other collectives like Newsreel utilized newly available $16 \mathrm{~mm}$ sync sound equipment, faster film stock, and lighter cameras to document the rise of the American counterculture and stimulate resistance to the war in Vietnam. This countercultural ethos was once again mirrored in the form of their films, all of which shunned voice-of-God narration in favor of observation and participant interviews. And finally, the work of filmmakers such as Jill Godmilow, Rea Tajiri, Jenny Livingston, Marlon Fuentes, and Marlon Riggs responded in the 1980 and 1990s to the culture war issues of the HIV/AIDS crisis, Reagan-era cutbacks of social welfare programs, the defunding of the arts, and other issues by turning to video to create deeply personal films meant to reflect the issues of specific subgroups. These performative films sought to bring what many had deemed the obscene "on/scene" by exploring the experiences and identities of these groups in a visible, mainstream form of media expression. ${ }^{28}$

These previous periods also demonstrate significant developments in documentary's rhetorical approach to what Jerry Kuehl calls its "truth claims" about the historical world. ${ }^{29}$ As different groups turn to documentary to further their social and political aims, they bring with them very different theoretical and philosophical influences, which in turn produce different rhetorical strategies for speaking about the world. As Jonathan Kahana points out, voice-of-God documentary in the 1930 s and 1940s, which sought to provide governmental transparency to the populace, originated in the pragmatist philosophy of thinkers like John Dewey, 
Walter Lippmann, and A. D. Lindsay. For these theorists and the filmmakers they influenced, the general public needed to understand the true nature of the complicated workings of large government bureaucracies; hence the need for films that performed this edifying function..$^{30}$ As historians of activist collectives like Newsreel have pointed out, theorists such as Herbert Marcuse influenced young activists to pursue independent representations of truth in opposition to the ideological truths of the state and mainstream media. In other words, countercultural filmmakers were offering the people's truth to counter the dominant state truth. ${ }^{31}$ Finally, films in the 1980s and 1990s reflect the "post" systems of thought (postcolonialism, postmodernism, post-Fordism) that deconstructed master narratives of truth, giving way to smaller-scale truth claims regarding the legitimacy of alternative identity formulations and a conscious utilization of aesthetic form as an expressive tool.

It is worth pointing out that the films that I am highlighting here and the innovative formal characteristics they exhibited do not necessarily represent the dominant or most popular styles of the time. Instead, they demonstrate relatively new modes of expression that came to characterize a particular political or ideological position within their respective contexts. This stylistic innovation emerged from creative uses of new technology - a move driven out of the desire to push political expression in new directions. But these formally inventive experiments emerged alongside plenty of more conventional work. Similarly, the characteristics that I will outline in the following chapters are not necessarily the dominant mode or style of post-9/11 documentary. Many remain one-off experiments that failed to generate any significant trend or imitation. Nonetheless, all are noteworthy because they managed to establish something new within the political conversation where they appeared. Many in fact achieved this influence because they originated from and came to represent previously marginalized groups. This was particularly the case with the formally innovative films that appeared in the late 1980 s and early 1990 os.

\section{THE AESTHETICS OF POLITICS}

The performative documentary of the late 1980 s and early 1990 deserves extended discussion, not only because it directly precedes the 9/11 political context but also because it was a point at which aesthetics self-reflexively emerge as a fundamental tool (one is tempted to say "weapon") for politically motivated work. Whereas the two prior periods utilized a particular aesthetic form to express and instantiate the political positions they espoused, for both, questions of aesthetics were an unacknowledged, almost regrettable, component of documentary expression. Indeed, one way to characterize the move from the institutionally driven, voiceof-God films to the Direct Cinema and Cinema Verite films is as a conscious 
move to limit artifice in favor of directly exposing or observing what was taking place before the camera.

For groundbreaking political filmmakers in the 1980s and 1990s, however, aesthetic form was consciously embraced as the fundamental ground on which the political battle was to be waged. As before, changes in production and distribution technologies (the emergence of consumer-grade video cameras and public access on expanding cable networks) emerged alongside a broader epistemological shift about the problematic nature of different forms of representation. Scholars and practitioners across fields such as history and anthropology as well as the arts and humanities began to question the ethics and accuracy involved in their work. As Hayden White demonstrated, clear distinctions between form and content blur to the degree to which meaning becomes a product of the particular narrative form that a given texts adopts. ${ }^{32}$ Ethnographic filmmakers like David MacDougall, building on the work of anthropologists like Clifford Geertz, began selfconsciously inserting themselves into their stories, implicitly undermining the objective authority once taken for granted by the camera/observer. In the work of practitioners and theorists such as Trinh T. Minh-ha, aesthetic form became central to documentary's legitimacy as a mode of expression rather than a regrettable drawback to be avoided at all costs. ${ }^{33}$

These insights shifted documentary expression past its "talking head" experts and fly-on-the-wall observations to a more experimental, expressive mode of representation that consciously utilized and maximized aesthetic form rather than minimizing its intrusions. Even a more mainstream filmmaker like Michael Moore, whose 1989 Roger \& $\mathrm{Me}$ falls directly within the performative era I am describing here, filters his populist politics through an individual, autobiographical framework, tracking the impact of capitalism on his hometown of Flint, Michigan, and appearing on-screen as the dominant persona of his films. During this period, documentary film, fine art, experimental film, video art, and grassroots activist practices all began to cross-pollinate. ${ }^{34}$ This created a level of fluid hybridity between forms and modes that would reemerge in the post-9/11 period.

But this prior period of political conflict and formal experimentation also provided a paradoxical legacy for documentary filmmakers and independent activists responding to the war on terror. On one hand, in $9 / 11$ and the war on terror they were confronted for the first time since the Vietnam War with an acute crisis of national magnitude. The scale of the conflict and the urgency of the issues at stake created the impulse to speak to the widest possible audience about divisive politi$\mathrm{cal}$ issues. On the other hand, they were utilizing a medium that seemed to have lost its rhetorical power to mobilize a mass population, one less willing than ever to take to the streets and march on anything. ${ }^{35}$ Indeed, the formal turn in documentary filmmaking during the 1980 os and 1990 s brought a conscious rejection of a single, universal political truth and a recognition that documentary aesthetics 
were part of the content of the form. This would seem to leave little space for either formal innovation or political engagement. And yet, the period after the 2000 presidential election and 9/11 ignited an era of widespread political engagement that was reflected in a surge of politically focused documentary film production. ${ }^{36}$

The convergence of political and technological forces cast all of the received categories up for grabs, creating an opening for this new period of formal evolution. Rather than a "universal truth," much of this experimentation was directed toward exposing a particular injustice against a common enemy. For example, many political documentary films began to levy their truth claims over and against those offered by the mainstream media, as Charles Musser has argued. ${ }^{37}$ That is, instead of purporting to present a state truth or an antistate truth, as films in the 1930s/1940s and 1960s/1970s did (or, in the case of 1980s documentary, an anti-normative truth), documentary films after 2000 counterpose their truth claims against an increasingly polarized and politically distrusted "media" truth. (For the political right, the object of this distrust is typically the New York Times, while for the left, the role is filled by Fox News.) This rejection of mainstream news sources only increased throughout this period, reaching a crescendo in the divisive relationship between Donald Trump and what he refers to as the "fake" mainstream news.

Moreover, in the last thirty years, documentary films that address political issues seem to have realized the futility of speaking to those beyond an audience of sympathetic viewers. While this audience has often been a specific constituency, the polarized political environment in the wake of the contested 2000 presidential election simplified and solidified these constituencies into two major wings. (To paraphrase George Bush's own terms, "You're either with us or against us.") This divisiveness enlarged the potential constituency for any given film to roughly half of the population. Thus, for the first time since Vietnam, documentary films had the freedom to speak to specific groups that were already inclined to believe the truth claims they presented about issues that affected everyone. This expanded audience provided the perfect environment for the renaissance of political documentary and documentary experimentation produced in the first decades of the twenty-first century. ${ }^{38}$

The historical legacy of documentary film as a viable form of political action and mobilization accounts for its reemergence on the national scene. As an activist form of independent media, documentary provided an alternative media model for a number of activists organizing in various digital environments. The generalized distrust of the mainstream media that characterizes our current moment partially explains the resurgence of documentary's popularity, but we should also attend to the incorporation of other alternative forms of participant media, from weblogs and podcasts to Twitter feeds and wikis. The same impulse that gave rise to political documentary films in prior moments is now a driving force in the 
way these other, newer forms of digital media are deployed in current social and political battles.

Each of the following chapters offers a comparative analysis of two different media objects or texts situated at some point along the spectrum between documentary film and digital media. I focus exclusively on the historical period that begins with the dot-com crash of 1999, the 2000 election, and the 9/11 terrorist attacks and ends with the election of Donald Trump. However, I draw on prior moments as they inform the central texts I consider. Given that many of the political issues that arose during the administration of George W. Bush scarcely subsided with the return to power of the Democratic Party and reemerged with the Trump administration, my concluding chapter follows this formal evolution into the era of "posttruth politics" and "fake news" that characterized the 2016 election.

Chapter 2 explores the impact of nonlinear digital editing and compositing programs on traditional documentary film by presenting a close reading of the recent work of Errol Morris-particularly his two films about war, politics, and technology: Standard Operating Procedure and The Fog of War. In the arc of Morris's career, the two films present something of a paradox. On one hand, both deploy all of the standard tropes of his by-now signature style: Interrotronenforced eye contact, richly staged reenactment, plentiful archival material, and visually dense montage sequences set to hypnotic music. Moreover, both films deal directly with questions of war, the military, and the mediated, moving-image representations we have of both. And yet these films respectively represent the high and low points of his career. Though somewhat controversial with critics for its treatment of Robert McNamara, The Fog of War generated nearly \$21 million at the box office and garnered Morris the Academy Award for Best Documentary. Going into Standard Operating Procedure, it seemed as though his films had finally received the mainstream attention and studio backing many felt he had always deserved. The success, however, was short-lived as the film debuted to even greater controversy and went on to fail commercially as well (earning just over \$300,000 total). Leaving aside why one film succeeded where the other failed, my reading claims that the controversial subject matter both explore allows Morris to address a larger point about the capability of media representation. I argue that this collage style is now the product of a certain form of database aesthetic in which the elements of the historical record (the archive) act as discrete elements that can be mixed and remixed depending upon the particular discursive context one wishes to construct. ${ }^{39}$

The irony inherent in his critique of media representation is that at this stage in his career Morris himself can almost be considered a multimedia artist. Both of these films were extensively expanded in companion books, and Morris contributes material regularly to a blog for the New York Times as well as to his webpage, 
ErrolMorris.com. That is, as Morris's films critique the omnipresence of representational recording technology and demonstrate the extent to which it can lead us to disastrous conclusions, his other outside activities contribute to the saturation he criticizes. These extracinematic materials also demonstrate the beginnings of a symbiosis between film and other forms of media.

But radical experimentation was also taking place elsewhere. If Errol Morris demonstrates the influence of digital technology and documentary's encroachment into other forms of media, Robert Greenwald's 2003-4 film Uncovered: The War in Iraq and its relationship to the political advocacy group MoveOn.org reveals a full-fledged interdependence between the two. As grassroots politicalorganizing groups moved into online spaces in the early days of the web, they pioneered the use of streaming video as a recruitment tool. Indeed, a quick glance at political-action websites from the period ranging from those on the left (Reprieve. org, Witness.org) to those on the right (RightMarch.com, TeaPartyPatriots.org) reveals a universal reliance on streaming video footage to articulate a group's message and document its past action. The use of video in these contexts demonstrates a crucial synergy between newly available online technologies and the century-old documentary tradition. As the social web slowly emerged and took shape in the early 20oos, online advocacy groups were experimenting with community building and online organizing. Documentary's ability to marshal evidence with argument to present a call to action found a natural home on websites capable of providing an immediate outlet for the impulse.

Chapter 3 analyzes one of the key historical moments in the remediation of nonfiction video and online political organizing: the 2004 collaboration of director Robert Greenwald (Outfoxed and Walmart: The High Cost of Low Prices) and the political action powerhouse MoveOn.org. This chapter provides both a historical account of the release of Outfoxed and an analysis of the extent to which MoveOn and Greenwald relied on one another to achieve their specific goals. Utilizing this cross-pollination as a case study, I analyze the mutual synergies between these two forms of media in order to demonstrate the necessity of each for the other as well as to interrogate the extent to which both forms still rely on real-world action to achieve their ends. Even as political action and its attendant images continue to move online, the goal remains to move people toward direct action in the real world. The efficacy of this new form of digital activism and its comparison with other forms of activism also form part of the story that unfolds here.

Whereas chapter 2 presents a traditional documentary film that bears some of the imprint of digital logic and chapter 3 explores the use of documentary images in online spaces, chapter 4 presents wholly digital media influenced by a documentary logic. It offers a comparative analysis of two online, interactive video games with clear political overtones. The first is the Gone Gitmo project, which 
attempted to re-create the real but inaccessible Guantánamo Bay prison complex in Second Life, a virtual but accessible online environment. The project uses various "documentary" sources for its re-creation and seeks to raise awareness about the political issues involved in the prison. The second is the America's Army video game, which, since 2002, has served as a recruiting tool for the US Army. The game offers players the chance to participate with other players in missions that simulate battles in Iraq and elsewhere. Although both games completely forsake the photographic indexicality that is documentary's tie to the historical world, both games utilize the documentary impulse to intervene in and motivate the individual to act in the real world. Both texts engage in a give-and-take exchange with reality in ways that mirror earlier documentary film efforts, and yet, the mechanisms that drive this exchange are clearly different. Such tactics were utilized by the state in propaganda training and recruitment films like the Why We Fight series in World War II and by individuals in both observational and performative documentaries in the 1970s and 1980s. As the cultural theorist Johan Huizinga points out, the move from spectator to player involves the participant in a methectic rather than mimetic relationship to the representation. This move gives Gone Gitmo and America's Army a powerful form of interpellation that engages participants in the new forms of subjectivity that both seek to achieve. ${ }^{40}$

Chapter 5 looks at the use of data visualization in government transparency initiatives during the first years of the Barack Obama administration. While Obama attempted to use twenty-first-century tools to create what he called "the most open administration ever," his efforts were ironically sidestepped by the unprecedented information releases of the anarchist/activist group WikiLeaks. At the same time that Obama was seeking to digitize and visualize government records, WikiLeaks was actively challenging the barriers between public and private entirely. Even as WikiLeaks reached for a series of optically driven Enlightenment metaphors to characterize its objectives (light, truth, sunshine, transparency), both utilized nonoptical media to achieve this. Moving from the documentary image to digital data in an aestheticized form, chapter 5 provides a historical look back into the history of the transparency debates while also looking forward to the shape these debates will play in coming decades.

Chapter 6 considers two of the primary by-products of the bitterly fought 2016 presidential election and the emergence of what many have characterized as the "posttruth" political style of its surprise winner, Donald Trump. The first is the role being played by conspiracy theory and paranoid speculation, both of which fueled Trump's entrée into national politics and clouded his ascension to the White House. Prior to the election, many of Trump's critics highlighted his relationship with dubious theories and fringe political figures, including Alex Jones of InfoWars, as evidence of his dangerous disregard for the truth. Exhibit 
A was Trump's promotion of "birtherism" (the theory that Barack Obama was not born in the United States) as a race-baiting means of gaining attention and undermining the legitimacy of the sitting president. After the election, however, as news began to circulate of possible Russian interference, election hacking, and secret dossiers, many of these critics fell victim to the same forms of conspiratorial speculation that just months earlier had seemed at best delusional, and at worst, irresponsible. As a form of independent speculation and alternative-media creation that seeks to question power and challenge existing narrative frameworks, conspiracy media and the theories it promotes offer a version of nonfiction media not entirely divorced from documentary film. And yet, the mode of paranoia and suspicion in which they operate forms a corrosive, adversarial context in which to debate and engage political ideas.

The second object this chapter considers is the emergence of a new breed of independent news outlet that I refer to as the "midstream media." Positioned between the mainstream media and the more fringe figures like Alex Jones, these midtier players exemplify the new breed of news organization that played a pivotal in the election and the so-called fake news debates that it produced. Steven Bannon's Brietbart News Network and Glen Greenwald's news organization The Intercept offer good examples of the midstream market more broadly. Ideologically, the two sites could not be further separated, and yet they bear a striking material resemblance to one another: both are independently funded by a select group of wealthy individuals, both occupy a position somewhere between mainstream media and the polarized extremes of independent media, and both critique the failure of existing media to hold governments accountable and provide truth to the public

While both of these developments (the rise of conspiracy media and the more polarized midstream media) seemed to emerge in the context of the 2016 election as endemic qualities of Trump and his unique political brand, this chapter demonstrates that both are the result of longer-standing trends in American political culture. Indeed, both emerge and grow as a result of the same forces that shaped all of the different objects that this book considers: a rapidly evolving media environment ever more suffused by digital technology, and a highly charged political environment that emerged in the wake of $9 / 11$. In this sense, the chapter continues the formal construction and political/technological focus of the earlier chapters while providing a conclusion to the argument as a whole.

Taken together, these chapters explore the emergence of the "digital documentary" by placing equal weight on both sides of the term, arguing that documentary informs the digital as surely as the digital informs documentary. As "data" becomes the central lens through which we view ourselves and the world around us, existing nonfiction practices such as documentary film will be the primary media that shape how digital media impact and express our individual worldviews. ${ }^{41}$ In 
seeking legitimacy as a mode of expression, digital media drew on the precedent set by documentary, and in grappling with the impact of digital media on our lives, documentary began to express the different fears and fascinations surrounding the transformation. If the first decades of the twenty-first century did indeed cast us into the dark, as our various political leaders would have us believe, it was a combination of both digital culture and documentary film that brought us back into the light - an evolution of forms and practices that worked to show us "where truth lies" for the century to come. 